\title{
Factors and survival of exclusive breastfeeding in preterm infants upon discharge at six months of age
}

\author{
Josefina Gallegos-Martínez ${ }^{* 1}$, Jaime Reyes-Hernández ${ }^{1}$, Fátima de San Carlos Torres-Carreón ${ }^{1}$, Blanca Esther \\ Cuéllar-Miranda ${ }^{1}$, Adriana Leite ${ }^{2}$, Carmen Gracinda Scochi ${ }^{2}$ \\ ${ }^{1}$ Universidad Autónoma de San Luis Potosí, Mexico \\ ${ }^{2}$ Escola de Enfermagem de Ribeirão Preto-USP-PAHO-WHO Collaborating Center for Nursing Research Development, Brazil
}

Received: February 4, 2020

DOI: $10.5430 /$ jnep.v10n8p30
Accepted: April 25, 2020

Online Published: May 10, 2020

URL: https://doi.org/10.5430/jnep.v10n8p30

\begin{abstract}
Introduction and objective: Reducing the neonatal mortality rate in half is an objective proposed by WHO for the year 2025 through coverage strategies from the prenatal stage, delivery, birth, and hospitalization, one of these low-cost strategies is exclusive breastfeeding (EBF) in preterm infants, that contributes to the prevention of neonatal mortality, a population that contributes in the first place to neonatal mortality. The objective of this study was to identify the frequency and survival of exclusive breastfeeding and related factors in premature infants of two referral hospitals, one of them certified as Baby-Friendly Hospital Initiative (BFHI).

Methods: Follow-up study of 111 premature infants after hospital discharge with equivalent corrected age among hospitals: BFHI $36.1 \pm 1.6$; non-BFHI (nBFHI) $36.4 \pm 1.8$ weeks ( $p \geq .05$ ). Data collection carried out from February 2016 to March 2017, through records in clinical files and surveys of mothers upon hospital discharge and by telephone during follow-up after 15 days post-discharge, 3 , and 6 months of extrauterine life. Kaplan-Meier analysis to determine breastfeeding survival over time, and with Pearson's $r$ with significance $p \leq .05$, the relation was established between EBF with sociodemographic, perinatal, and clinical status factors of the child.

Results: Urban maternal origin (68.1\%), maternal age $(25.7 \pm 7.9$ years), schooling $<12$ years $(56.6 \%)$. EBF upon discharge on $45 / 111$ dyads (40.5\%), 15 days post-discharge 35/73 (47.9\%), third month $23 / 61$ (37.7\%) and sixth month 7/44 (15.9\%). EBF survival was 15 days post-discharge, at this cut-off point, among the correlated factors are: "having received guidance to use Exclusive Breastfeeding until the sixth month of extrauterine life of the premature child" positively correlated with EBF $(r=0.294, p \leq .05)$, "the maternal perception that her milk dried" correlated negatively with EBF $(r=-0.313, p \leq .01)$, if "breastfeeding caused anxiety to the mother" it positively correlated with artificial feeding (AF) $(r=0.237, p \leq .05)$.

Conclusions: Exclusive breastfeeding in premature infants is below WHO standard, it is favorably related to maternal orientation, and barriers are maternal perceptions of non-milk supply and anxiety. It could be encouraged through actions carried out in hospitals certified with the Baby-Friendly Hospital Initiative and follow up with post-discharge breastfeeding at least to the sixth month of life of premature infants. Similar studies should establish better monitoring mechanisms to avoid losses during the follow-up.
\end{abstract}

Key Words: Maternal breastfeeding, Infant premature, Kangaroo-mother method

\section{INTRODUCTION}

According to the World Health Organization (WHO) premature birth occurs between $5 \%$ to $18 \%$ in the world and $8.6 \%$ in Latin America. Premature birth is the leading cause of neonatal mortality and the second leading cause of mortality in children under 5 years of age. If these children survive,

*Correspondence: Josefina Gallegos-Martínez; Email: jgallego@uaslp.mx; Address: Universidad Autónoma de San Luis Potosí, Mexico. 
they are at high risk for various complications and/or disability. In this regard, WHO proposed the goal of reducing neonatal mortality by 2025 mainly in countries with a Live Newborns rate $\geq 5 \times 1,000$, through priority interventions based on scientific evidence such as coverage and care from the prenatal stage to prevent premature birth, and to prevent deaths of premature infants at birth during delivery and in neonatal care rooms that include, basic resuscitation treatments, respiratory support, infection prevention, nutritional support, and well-selected intensive care, as well as low-cost strategies for small preterm infants such as the kangaroo mother method (KMM) and EBF. ${ }^{[1]}$ Which is also supported by the recent proposal "Decade of Action on Nutrition 20162025" of the United Nations (UN) and WHO, for reducing hunger and malnutrition with the fulfillment of six nutrition global targets, the fifth one specifies the increase in the rate of EBF for at least the first six months of life in $50 \%$ of the cases. $^{[2]}$

There is scientific evidence that EBF in the first hour of life and the first six months of the child's life contribute to the reduction of infant mortality. This breastfeeding practice is fostered through the Baby-Friendly Hospital Initiative (BFHI). In estimating the impact of BFHI in Brazil, secondary data from the study of the prevalence of breastfeeding in 2008 were used, showing the increase in the rate of EBF and any other type of breastfeeding in the first hour of life and its influence on $4.2 \%$ reduction in infant mortality. The BF in the first 6 months of life of children born in BFHI hospital, had the effect of reducing deaths from any cause and infection. ${ }^{[3]}$ In a neonatal network of 18 neonatal units in the United Kingdom with the "Getting It Right From the Start Programme" intervention, the rate of EBF and motherchild skin-to-skin method was increased and this associated with the decrease in costs due to gastroenteritis (GE) and necrotizing enterocolitis (NEC) in more than half a million pounds sterling, as demonstrated by a cost-benefit study. ${ }^{[4]}$ The establishment of EBF is favorably influenced thanks to BFHI or related practices, even so, difficulties are seen in the application of some of its components, such is the case of prenatal education about EBF (step 3) and in support for postnatal EBF (step 10) associated with a shorter duration of EBF. ${ }^{[5]}$

Despite favorable evidence, the prevalence of breastfeeding in children under six months of age is less than $37 \%$, especially in countries with low and medium development, although developed countries are not exempt from abandoning EBF. ${ }^{[6]}$ Prematurity and Low Birth Weight (LBW) are associated with the withdrawal of EBF before the six months of extrauterine life (EUL), thus, 286 of Vietnamese moth- ers intending to feed with EBF for at least six months, 70\% used EBF and comparatively between term and premature children, the latter were disadvantaged $(80 \%$ and $20 \%$ respectively). ${ }^{[7]}$ In Australia, in a study on EBF that began in hospitalization, $40.8 \%$ of 2,148 mothers continued with EBF until the six months of EUL (70\% EBF and 29.8\% partial $\mathrm{BF})$, in the rest of the mothers the associated factors to early cessation were mainly prematurity and LBW, among others. ${ }^{[8]}$

In the case of Mexico, the BF index is suboptimal according to WHO recommendations and fell from $22.3 \%$ in 2006 to $14.4 \%$ in 2012 , Mexican women aged 12 to 49 years revealed that among the reasons for never breastfeeding their children, were having had a premature child (8th place of the causes-National Survey of Health and Nutrition-ENSANUT 2012). ${ }^{[9]}$ In recent data from the National Survey of Demographic Dynamics (ENADID), regarding BF practices in women aged 15 to 49 years from the period from January 2009 to September 2014, 91.4\% of newborns received breast milk, from which only $11 \%$ had EBF. ${ }^{[10]}$ The Mexican health system proposed the National Breastfeeding Strategy 2014-2018 to raise the EBF rate according to WHO recommendations, ${ }^{[11]}$ and to be inclusive it would also have to be extended for premature-born children. Cost estimates of inappropriate practices of BF in Mexico are between $\$ 11,100$ and 36,200 million pesos annually, of which $11 \%$ to $38 \%$ of the cost is used to buy breast milk substitutes, especially in poorer families. Morbidity in children under one year not being breastfed is related mainly to acute diarrhea, necrotizing enterocolitis, and respiratory infections. ${ }^{[1]}$ In that regard, economic benefits and family financial protection would be obtained if expenses were not incurred for the purchase of substitutes and disease treatments, as well as for the health system as the investment in health would be reduced.

Despite efforts to increase EBF in premature infants, actually that three types of feeding are mainly reported, (EBF), mixed lactation (MBF) and artificial feeding (AF), thanks to which there may or may not, be a difference in the increase in weight and/or height of premature infants, as growth is considered the most sensitive index for assessing health, nutrition, and neurodevelopment. ${ }^{[12]}$ A qualitative study revealed that for mothers of preterm inpatients "health is related to the corporality of the preterm infant", thus, weight represents the key to health. ${ }^{[13]}$ A Brazilian cohort of 42 preterm infants with 40 weeks of corrected age and with assessment at different cut-off points for home follow-up (at 15 and 45 days after hospital discharge, at the third and sixth month of life), studied the prevalence of types of feeding and weight gain. At 15 days the EBF had the highest peak (71.5\%), followed 
by MBF (19\%) and finally, AF (9.5\%) and the average daily weight gain in preterm infants was $18.16 \mathrm{~g}, 13.37 \mathrm{~g}$ and 21.17 g per day for $\mathrm{EBF}, \mathrm{MBF}$, and AF respectively. At this cut-off point, the AF effect was of greater weight gain. However, on day $45(45.2 \%)$ and at the third month $(38.1 \%)$, despite the decrease in the prevalence of EBF, the mean weight gain was greater in preterm infants, thus, the mean was $39.17 \mathrm{~g}$, $36.59 \mathrm{~g}$ and $31.14 \mathrm{~g}$ for EBF, MBF, and FA, respectively, the nutritional component of human milk was higher than that of FA, a situation that was reversed at the sixth month, in which FA raised the prevalence to $59.5 \%$ and the daily mean weight gain was $20.62 \mathrm{~g}$, which exceeded $17.03 \mathrm{~g}$ and 18.58 $\mathrm{g}$ of EBF and MBF respectively. ${ }^{[14]}$ In a similar study in the Latin population, the anthropometric changes (weight and height gain) of 48 preterm infants and the type of feeding were analyzed, concerning the EBF, which was controlled through the ingestion of the three fractions of milk intake: solution, suspension and the final fraction of emulsion with higher caloric density due to its lipid content. Thus, through the initial and final assessments of approximately 4 weeks, no significant differences were found in the average daily weight gain, of $32.4 \pm 9.2 \mathrm{~g}, 32.0 \pm 7.0 \mathrm{~g}$ and $36.2 \pm 7.3$ $\mathrm{g}$ with $\mathrm{EBF}, \mathrm{MBF}$, and AF respectively and neither the size had a significant difference between the different types of feeding, $0.15 \pm 0.06 \mathrm{~cm}, 0.13 \pm 0.05 \mathrm{~cm}$ and $0.16 \pm 0.07$ $\mathrm{cm}$ for EBF, MBF, and AF respectively. ${ }^{[15]}$ In addition to the decrease in morbidity, weight gain is highly valued as a sign of good clinical evolution of the preterm infant.

Few studies have focused on EBF in premature children in Mexico, therefore this study intends to provide evidence, that although it is local, it can help to substantiate strategies of health professionals and institutions that certify in BFHI and also encourage EBF in the premature population.

\section{Objective}

Identify the frequency and survival of exclusive breastfeeding and related factors in premature infants of two referral hospitals, one of them certified as Baby-Friendly Hospital.

\section{METHODS}

Follow-up study of premature infants upon discharge at six months of age, follow-up after 15 days post-discharge, 3 and 6 months of extrauterine life.

\subsection{Sample}

For convenience and recruitment by quota of 111 motherpremature infant dyads admitted to two referral hospitals (one BFHI), since hospital discharge with signed informed consent. The starting point was recorded upon discharge by the equivalence of the populations of both hospitals accord- ing to the corrected age upon discharge, (BFHI $36.1 \pm 1.6$; nBFHI -NCH $36.4 \pm 1.8$; student $t=-0.797, p \geq .05)$.

\subsection{Instrument}

The project survey "Research: Breastfeeding in preterm infants: impact of the Child Friendly Hospital Initiative for neonatal units" of the Department of Maternal and Child Nursing and Public Health in the Escola de Enfermagem, Universidade de São Paulo, Brasil-WHO Collaborating Center. The survey was raised based on the respective literature and collects information on EBF and associated factors: rural/urban residence, occupation, monthly income, marital status, schooling, and maternal age, prematurity, LBW, grand multiparity, cesarean section, Kangaroo-mother method (KMM), BFHI, support for EBF, rooming-in, skinto-skin contact, the intention of EBF, initiation of EBF in the first hour of EUL, among others. ${ }^{[16-22]}$

The survey consists of three sections: a) Sociodemographic data collected by interview with the mother (rural or urban address, age, schooling, and current maternal and paternal work and monthly family income). b) Perinatal history collected from the clinical record: pregnancy, births, pathologies in pregnancy and childbirth, weight and gestational age at birth, type of delivery, number of products, 1 and 5 minutes APGAR scores, neonatal resuscitation, site and duration of hospitalization, pathologies during hospitalization, ventilatory assistance and oxygen therapy, length of hospitalization in rooming-in or KMM. Previous breastfeeding, skin-to-skin contact, time of onset of breastfeeding, type of feeding during hospitalization, and hospital discharge. c) Follow-up at home applied by telephone interview at the post-discharge cut-off points: 15 days, 3 and 6 months of life on type of BF, causes of abandonment, opinions on hospital care in support of breastfeeding, maternal perceptions about breastfeeding (desire to breastfeed, feelings, obstacles, support), maternal suggestions to improve the support of the health team for breastfeeding in premature infants. The validation and cultural adjustment were carried out through application to 12 mothers with premature children in the neonatal unit of a hospital/maternity ward. It was translated of Portuguese into Spanish by the principal researcher and the correct adaptation of the Spanish language and culture was corroborated by a pilot test applied in a similar population.

\subsection{Data analysis}

A database was prepared for analysis in the IBM SPSS statistics version 20. Descriptive statistics were used in categorical variables, Pearson's $r$ (significance $p \leq .05$ ) to establish the relationship between EBF and other factors and the KaplanMeier analysis to establish the EBF survival curve over time. 


\subsection{Ethical aspects}

The project was approved by the Research Ethics Committee of the Faculty of Nursing and Nutrition, UASLP (Registry CEIFE-2015-150) and of the hospitals studied, BFHI HNM/02-2016/036 and nBFHI registry 11-16.

\section{Results}

\subsection{Study population}

The sample collected at discharge ( $\mathrm{s}=111$ dyads $), 15$ days after discharge $(\mathrm{s}=73), 3$ months EUL $(\mathrm{s}=61)$ and 6 months EUL $(s=44)$. The losses were due to the death of four premature infants and the rest corresponded to mothers who did not wish to continue in the study, as well as difficulties with contact in the telephone follow-up (lack of signal for their mobile phone and lack of access to the single landline in rural communities). The characteristics of the study population are shown in Table 1, the majority of mothers are of urban origin and over 20 years of age, although it is relevant that a third are adolescents. The majority with low schooling (under 12 years of study) and the vast majority are living with the father of the premature child and are engaged in household chores and with a low monthly salary less than a Mexican minimum wage. The majority of births were cesarean sections with late premature infants and as the main comorbidity at birth the respiratory distress syndrome. Skin-to-skin contact was initiated only in $12.1 \%$ but breastfeeding began in the first hour of life only in $3.4 \%$ (see Table 1 ).

\subsection{Frequency of breastfeeding types}

The frequency of EBF was observed in less than half of the population of premature infants upon discharge, at home in the first 15 days post-discharge EBF achieved a small increase, however, it decreased significantly towards the sixth month of EUL in contrast with the increase in the frequency of use of AF. The reduction of the MBF is also observed from discharge until the sixth month EUL, which means less supply of human milk in premature breastfed infants (see Table 2).

The frequency of EBF was different among the population of premature children, higher percentage in children admitted to the BFHI upon discharge, at 15 days post-discharge, and 3 months of EUL, in the sixth month of EUL the frequencies of EBF of both hospitals matched. The PBF was always maintained with low frequency throughout the follow-up and the MBF had the highest rate at discharge, it matched EBF at 15 days and third-month post-discharge and was considerably abandoned in favor of AF (see Table 3).

According to the Kaplan-Meier survival analysis, the median duration of EBF in the mother-premature child dyads of both hospitals together had a duration of 15 days post-discharge
(CI 95\%). It is graphically seen that the EBF was higher in the BFHI during the follow-up (see Figure 1).

Table 1. Characteristics of the mother-premature child dyads admitted to two referral hospitals

\begin{tabular}{|c|c|}
\hline Factor & $\begin{array}{l}\text { Total } \\
\text { f (\%) }\end{array}$ \\
\hline \multicolumn{2}{|l|}{ Origin } \\
\hline Rural & 37 (31.9) \\
\hline Urban & $79(68.1)$ \\
\hline \multicolumn{2}{|l|}{ Maternal age (years) } \\
\hline$<20$ & $35(30.2)$ \\
\hline$\geq 20$ & $81(69.8)$ \\
\hline \multicolumn{2}{|l|}{ Maternal schooling (years) } \\
\hline$<12$ & $66(56.6)$ \\
\hline$\geq 12$ & $50(43.4)$ \\
\hline \multicolumn{2}{|l|}{ Maternal occupation } \\
\hline Housework & $95(81.9)$ \\
\hline Student & $6(5.2)$ \\
\hline Other & $15(13.9)$ \\
\hline \multicolumn{2}{|l|}{ Maternal marital status } \\
\hline Married/Domestic partnership & $101(87)$ \\
\hline Single & $15(13.0)$ \\
\hline \multicolumn{2}{|l|}{ Family monthly income* } \\
\hline$<1$ minimum wage & $60(56.1)$ \\
\hline$\geq 2$ minimum wages & $47(43.9)$ \\
\hline \multicolumn{2}{|l|}{ Type of pregnancy } \\
\hline 1 product & $97(83.6)$ \\
\hline$\geq 2$ products & $19(16.4)$ \\
\hline \multicolumn{2}{|l|}{ Type of delivery } \\
\hline Vaginal & $50(43.1)$ \\
\hline Cesarean section & $66(56.9)$ \\
\hline \multicolumn{2}{|l|}{ Newborn Sex } \\
\hline Female & $54(46.6)$ \\
\hline Male & $62(53.4)$ \\
\hline \multicolumn{2}{|l|}{ Gestational Age (weeks) } \\
\hline$<32$ & $24(20.7)$ \\
\hline$\geq 32-36^{+6}$ & $92(79.3)$ \\
\hline \multicolumn{2}{|l|}{ Weight at birth (grams) } \\
\hline$<1,500$ & $37(31.9)$ \\
\hline $1,500-2,499$ & $64(55.1)$ \\
\hline$\geq 2,500$ & $15(13.0)$ \\
\hline Complications at birth & $40(34.5)$ \\
\hline Complications at hospitalization & $84(72.4)$ \\
\hline Previous breastfeeding & $52(45.2)$ \\
\hline \multicolumn{2}{|l|}{ Initiation skin to skin contact } \\
\hline Immediately at birth/first hour & $15(12.1)$ \\
\hline $2-24 \mathrm{~h}$ & $6(5.2)$ \\
\hline$>48 \mathrm{~h}$ & $96(82.8)$ \\
\hline Breastfeeding in the first hour of life & $4(3.4)$ \\
\hline Respiratory distress syndrome & $53(45.7)$ \\
\hline Sepsis & $37(31.9)$ \\
\hline Necrotizing Enterocolitis & $6(5.2)$ \\
\hline MC Stay & $18(16.2)$ \\
\hline Rooming-in Stay & $29(26.1)$ \\
\hline Hospitalization Duration (mean \pm SD) & $16.4 \pm 17.7$ \\
\hline$<1$ week & $40(35.7)$ \\
\hline$\geq 1$ week and $<1$ month & $54(44.5)$ \\
\hline$\geq 1$ month & $22(19.8)$ \\
\hline
\end{tabular}


Table 2. Frequency of types of breastfeeding of premature infants according to WHO since discharge at 6 months of life in two referral hospitals

\begin{tabular}{|c|c|c|c|c|c|c|c|c|}
\hline & \multicolumn{2}{|c|}{ Discharge } & \multicolumn{2}{|c|}{15 days post-discharge } & \multicolumn{2}{|c|}{3 months EUL ${ }^{\&}$} & \multicolumn{2}{|c|}{6 months EUL } \\
\hline & f & $\%$ & f & $\%$ & f & $\%$ & f & $\%$ \\
\hline $\mathrm{EBF}^{*}$ & 45 & 40.5 & 35 & 47.9 & 23 & 37.7 & 7 & 15.9 \\
\hline $\mathrm{PBF}^{\dagger}$ & 1.0 & 0.9 & 2 & 2.7 & 3 & 4.9 & 2 & 4.6 \\
\hline $\mathrm{MBF}^{\#}$ & 55 & 49.6 & 24 & 32.9 & 17 & 27.9 & 9 & 20.9 \\
\hline $\mathrm{AF}^{\S}$ & 10 & 9 & 12 & 16.5 & 18 & 29.5 & 26 & 59.0 \\
\hline $\mathrm{n}=$ & 111 & 100 & 73 & 100 & 61 & 100 & 44 & 100 \\
\hline Lost & 0 & & 38 & & 12 & & 17 & \\
\hline
\end{tabular}

Note. Source: Survey ${ }^{*}$ Exclusive breastfeeding ${ }^{\dagger}$ Predominant breastfeeding ${ }^{\#}$ Mixed breastfeeding ${ }^{\$}$ Artificial feeding ${ }^{8}$ Extrauterine life of premature babies.

Table 3. Frequency of breastfeeding according to WHO classification, in premature infants of two referral hospitals BFHI and $\mathrm{nBFHI}$

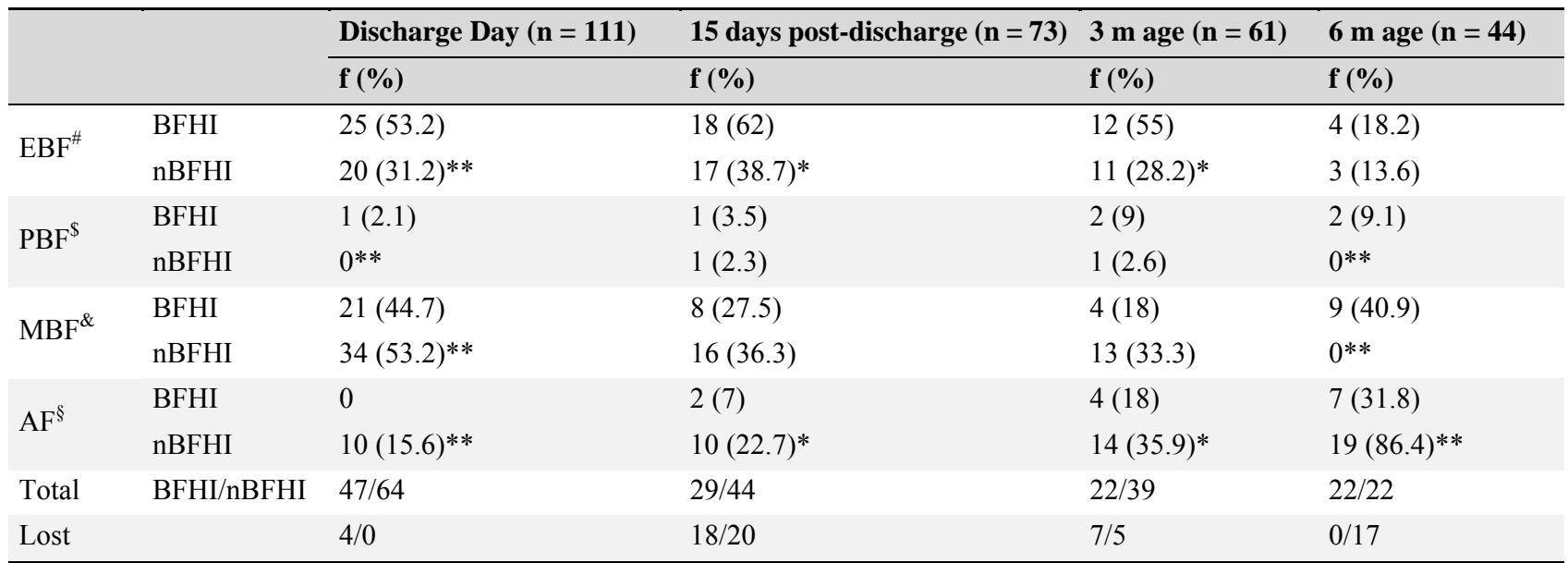

Note. Source: Survey. ${ }^{\#}$ Exclusive breastfeeding; ${ }^{S}$ Predominant breastfeeding; ${ }^{8}$ Mixed breastfeeding; ${ }^{\S}$ Artificial feeding; Student $t$-test for independent samples between hospital with Baby-Friendly Hospital Initiative (BFHI) and non- Baby-Friendly Hospital Initiative (nBFHI). ${ }^{*} p \leq .05, * * p \leq .01$

3.3 Factors related to exclusive breastfeeding of prema- facilitators and barriers to EBF continuity (see Table 5). ture infants upon discharge at six months

Table 4 shows the factors correlated with the types of breastfeeding in the study population. Maternal factors that act as a barrier to EBF in premature infants are related to low or absent milk supply, maternal health condition, lack of desire to breastfeed, and anxious emotional state. Neonatal factors were related to their state of prematurity such as difficulty in suction and prolonged hospitalization. When guidance was received for EBF and the express breast milk technique, and not feeling supported by the EBF health team, and seeking and receiving guidance from the pediatric breastfeeding physician, the MBF was offered to the child (see Table 4).

\subsection{Maternal perceptions and opinions}

The mothers' point of view of premature infants was collected at 15 days post-discharge since it was at this cut-off point that EBF was yet continued at least in the median of the dyad and the experiences regarding EBF can define



Figure 1. Survival function 
Table 4. Factors related to the types of breastfeeding in premature infants in two referral hospitals

\section{Factors}

She is not breastfeeding because her milk dried

She is not breastfeeding because she had little milk

$\begin{array}{lll}\mathbf{E B F}^{\#} & \mathbf{M B F}^{\mathbf{8}} & \mathbf{A F}^{\dagger} \\ -0.313^{* *} & & 0.378^{* *} \\ -0.287^{*} & & \end{array}$

She is not breastfeeding due to suction difficulties since hospitalization

She is not breastfeeding because she did not want to breastfeed

She is not breastfeeding due to maternal disease

Received guidance for EBF upon discharge

Received guidance upon discharge for breast care

$0.279^{*}$

Received guidance upon discharge for expression technique

Received guidance upon discharge for duration of EBF for a minimum of 6 months of the child's life

$0.294 *$

Received guidance upon discharge to do MBF

$0.286^{*}$

She felt assisted by the health team for EBF

She sought and obtained help for BF with a pediatrician

Breastfeeding makes her feel happy for the daily achievements

Breastfeeding makes her feel confident in the child's improvement

Breastfeeding makes her feel that she contributes to the child's health

$0.285^{*}$

Breastfeeding makes her feel she needs to provide a supplement

Breastfeeding makes her feel anxious

Breastfeeding makes her feel she has little milk

$0.237^{*}$

Note. Source: Survey. ${ }^{\#}$ Exclusive breastfeeding ${ }^{\S}$ Mixed breastfeeding ${ }^{\dagger}$ Artificial feeding. Pearson's $r$ test, $p \leq .05,{ }^{* *} p \leq .01$

Table 5. Opinions, perceptions, and maternal guidance on Exclusive Breastfeeding in the premature child at 15 days post-hospital discharge in two referral hospitals BFHI and nBFHI $(n=73)$

\begin{tabular}{|c|c|}
\hline ITEM & $f(\%)$ \\
\hline Wished to breastfeed & $69(97.2)^{\sharp}$ \\
\hline \multicolumn{2}{|l|}{ Maternal reasons to stop breastfeeding } \\
\hline $\begin{array}{l}\text { "Breastfeeding problems since hospitalization" } \\
\text { (Difficulties for suction, breastfeeding technique, a prolonged stay of the premature infant, maternal disease) }\end{array}$ & $27(37.0)$ \\
\hline "Milk dried or she had little milk" & $20(27.4)$ \\
\hline "Breast problems" & $10(13.7)$ \\
\hline \multicolumn{2}{|l|}{ Perception of support by the health team } \\
\hline "She felt supported by the health team" & $57(77.0)$ \\
\hline \multicolumn{2}{|l|}{ She received guidance for $B F$ upon discharge } \\
\hline BF Technique & $41(57.7)$ \\
\hline BF Importance & $21(29.2)$ \\
\hline Feeding every 3 hours & $21(29.2)$ \\
\hline Feeding on demand & $15(20.8)$ \\
\hline Breast care & $13(18.1)$ \\
\hline Alternate breast & $12(16.7)$ \\
\hline EBF minimum to the sixth month of EUL & $11(15.3)$ \\
\hline Expression Technique & $10(13.9)$ \\
\hline Fluid intake and maternal nutrition & $10(13.9)$ \\
\hline Hand washing before BF & $6(8.3)$ \\
\hline KMM & $5(6.9)$ \\
\hline \multicolumn{2}{|l|}{ Sought and obtained help for post-discharge BF } \\
\hline Another place (not health personnel or family member) & $20(32.3)$ \\
\hline Milk bank, nurse, doctor & $8(11.2)$ \\
\hline Family member & $4(5.6)$ \\
\hline \multicolumn{2}{|l|}{ Opinions to improve support for BF in premature infants } \\
\hline "Continue support for BF, improve health human resources, more humanized and improve teaching to the mother" & $41(58.6)$ \\
\hline
\end{tabular}




\section{DiscuSSION}

The prevalence of EBF upon discharge in the study population was less than $50 \%$, in a developed country two-thirds of premature infants were exclusively breastfed upon discharge, the data were obtained from the Prospective National Cohort Study in Denmark. ${ }^{[19]}$ EBF in premature infants in developed countries is higher mainly because it is culturally inherent to the maternal role and has the motivation provided by their health and social systems. The onset of EBF in the first hour of life is a crucial moment to establish adherence to breastfeeding, in this study it occurred only in $3.4 \%$ unlike in Arab countries with a $100 \%$ onset in premature infants and LBW. ${ }^{[23]}$

Maintaining EBF for at least six months is difficult, in the survival analysis of this study $50 \%$ of the population of premature children was in EBF at 15 days post-discharge, an index that is well below the recommendations of WHO to maintain it at least up to the sixth month of EUL, and much lower than in other developing countries, as is the case of two cohorts of premature infants in Brazil in which the survival of EBF was of five and two months respectively, ${ }^{[24,25]}$ and 6-month survival was reported in Ethiopia. ${ }^{[26]}$ Each context differs in the survival of EBF according to the factors that affect the duration, which is influenced by maintenance in previous periods, in that sense, in a survey at the fourth and fifth month postpartum applied to 797 American mothers who initiated with EBF at birth, it was shown that nine weeks of EBF maintenance were required to, in turn, keep EBF at three months and 14.9 weeks of exclusivity were required to achieve EBF at five months, mothers who had completed nine weeks in EBF were 2.2 times more likely to continue EBF at three months. ${ }^{[27]}$

Insufficient milk supply is a factor for EBF failure reported in different contexts, and it was also revealed in this study in the perception of $27.4 \%$ of mothers at 15 days post-discharge follow-up of "having little milk" or "it dried up", in that regard $44 \%$ of Arab mothers also referred to having low milk supply as a frequent reason to stop breastfeeding. ${ }^{[23]}$ For Mexican experts in breastfeeding, it could be considered that there is a certain degree of truth in the low milk supply explained by the obstacles in the phases of milk supply, including breast problems, a factor that in this study, consistently correlates at different times of the follow-up.

Among the barriers to establishing and adhering to EBF are the cultural aspects, in a qualitative study on maternal representations of health and breastfeeding in premature children, the topic "choice of the best food of breast milk versus formula" was revealed, maternal representations that come from their cognitive construction and of the environment that demerit $\mathrm{EB}$, both refer to poor milk production, and the "harm" it causes to the child. Although also among the reasons to abandon breastfeeding is the medical prescription to suspend it. ${ }^{[13]}$ Currently, the Mexican clinical guidelines for enteral feeding of preterm infants of 32 weeks or less of gestational age include the use of formulas for preterm infants. ${ }^{[12]}$ This is part of the challenges for BFHI hospitals and health personnel.

These aspects should be addressed when counseling the nursing mother considering their perception as something closer to what is actual and not as a mere disdain for breastfeeding and thus through support reduce the barriers to remain in the EBF.

Schooling and low socio-economic status are factors current in this study, if the mother does not have the economic and welfare benefits and is of lower educational level, early weaning occurs before six months as also was revealed in the study of the socio-economic impact on the duration of EBF in Sweden, although breastfeeding is a cultural part of the maternal role and child care, ${ }^{[28]}$ and maternal schooling was associated with a duration longer than four months of EBF in the LBW neonates in a Brazilian cohort, the failure in the duration of EBF in premature children in Denmark was attributed to low and intermediate maternal schooling. ${ }^{[19]}$ The mother's work activity can be an important barrier to breastfeeding in Mexican women. ${ }^{[11]}$ It is known that there are no working conditions for the mother to express and preserve milk during working hours, an issue that is already addressed in the National Breastfeeding Strategy 2014-2018 in Mexico. ${ }^{[29]}$ Mothers report in different studies that they abandon EBF due to illness, in Mexico, this is a challenge that could be faced if milk banks could be increased, in 2016 there were only 19 in the country, which translates into an index of 0.6 banks for each of the 31 states of Mexico. ${ }^{[10]}$

In addition to the personal and interpersonal factors of the premature mother-child dyad related to EBF, health policies affect the success of breastfeeding. Studies report that BFHI practices contribute to raising the frequency and continuity of EBF in hospitalized premature infants, success in EBF in premature infants in Malaysia and Denmark was associated with rooming-in and skin-to-skin contact practices, the KMM practices by Italian mothers was a facilitator for EBF, similar to what was observed in this study. ${ }^{[17,19,20]}$ In that regard, in 2017 in the United States of America a survey was applied to mothers regarding their participation in BFHI practices, the findings showed that the EBF rose from $31.2 \%$ to $59.3 \%$ and the use of the bottle was reduced from $86.1 \%$ to $55.3 \%$ between 2008 and 2017 respectively. ${ }^{[30]}$ In the case of Mexico with 352 recertified hospitals for 2015 a data not comparable 
with the 767 that were certified between 1993 and 2003, , $^{[1]}$ there is still a way to go to raise the prevalence of EBF in the neonatal and particularly in the preterm population.

\section{Conclusions}

The frequency of EBF since discharge to the sixth month of life is below WHO recommendations that it be provided up to at least $50 \%$ of the nursing infants.

Breastfeeding survival up to 15 days post-discharge in the study population is well below the recommended time by WHO for a minimum duration of six months of age with EBF.

The BFHI certified hospital had better rates of EBF upon discharge. Since the 15 days and the third month of life of the preterm babies, higher rates of EBF were observed concerning the non-certified hospital, which is not entirely conclusive due to the high loss rate of the studied population.

\section{Limitations}

Study of local scope regarding the context where it was carried out. The sample was not calculated and randomized to make it possible to have transferable results, the sample was recruited from volunteers because the neonatal units have few censurable beds in the neonatal units despite being referral hospitals. The population was reduced considerably, the mothers of rural domicile (third part) were lost from the first follow-up by not having accessible telephone means. On the other hand, it was up to the decision of the participants to continue especially in the urban area, they did have a mobile phone in the vast majority of cases and could respond directly to follow-up calls, some expressed the desire to withdraw, at other times the mother, mother-in-law or husband responded without providing sufficient information and had to be removed from the sample.

Finally, unlike other contexts in developed countries that have systematized birth and health records with follow-ups, there is no post-discharge follow-up through the health centers or medical units in the health system, which hinders any monitoring of populations since hospital discharge.

\section{ACKNOWLEDGEMENTS}

Programa de fortalecimiento (Program for strengthening educational quality) P/PPFCE-2016-24MSU0011E-10.

\section{CONFLicts OF INTEREST Disclosure}

The authors declare that there is no conflict of interest.

\section{REFERENCES}

[1] March of Dimes, PMNCH, Save the Children, WHO. Born too soon: The Global Action Report on Preterm Birth. Eds CP Howson, MV Kinney, JE Lawn. World Health Organization, Geneva. 2012.

[2] WHO. Essential Nutrition actions: mainstreaming nutrition through the life-course. Geneva: World Health Organization; 2019.

[3] Silva OLO, Rea MF, Venâncio SI, et al. The Baby-Friendly Hospital Initiative: increasing breastfeeding and decreasing infant mortality in Brazil. Rev. Bras. Saúde Mater. Infant. 2018; 18(3): 481-489. https://doi.org/10.1590/1806-93042018000300003

[4] Lowson K, Offer C, Watson J, et al. The economic benefits of increasing kangaroo skin-to-skin care and breastfeeding in neonatal units: analysis of a pragmatic intervention in clinical practice. International Breastfeeding Journal. 2015; 10: 11. PMid:26000029 https://doi.org/10.1186/s13006-015-0035-8

[5] Munn AC, Newman SD, Mueller M, et al. Impact of the BabyFriendly Hospital Initiative. Breastfeeding Medicine; 2016; 11(5).

[6] Víctora CG, Bahl R, Barros AJD, et al. Breastfeeding in the 21st century: epidemiology, mechanisms, and lifelong effect. Lancet Series Breastfeeding. January 30, 2016; 387: 475-490. https: //doi.org/10.1016/S0140-6736(15)01024-7

[7] Nguyen PTK, Tran HT, Thai TTT, et al. Factors associated with breastfeeding intent among mothers of newborn babies in Da Nang, Viet Nam. International Breastfeeding Journal. 2018; 13(2): 1-7. PMid:29344079 https : //doi .org/10.1186/s13006-017-014 4-7

[8] Quinlivan J, Kua S, Gibson R, et al. Can we identify women who initiate and then prematurely cease breastfeeding? An Australian multicentre cohort study. International Breastfeeding Journal. 2015; 10: 16. PMid:25941535 https://doi .org/10.1186/s13006-0 15-0040-y

[9] Unar-Munguía M, Stern D, Colchero MA, et al. The burden of suboptimal breastfeeding in Mexico: Maternal health outcomes and costs. Matern Child Nutr. 2018; e12661. PMid:30136370 https : //doi.org/10.1111/mcn. 12661

[10] Instituto Nacional de Geografia e Informatica (INEGI). Practice of Breastfeeding in Mexico. An Analysis with Data from the National Survey of Demographic Dynamics (ENADID) 2018.

[11] González-de Cosío T, Hernández-Cordero S (Editoras). Lactancia materna en México. Consejo Nacional de Ciencia y TecnologíaAcademia Nacional de Medicina México-Intersistemas EditoresMéxico. 2016. 178 pp.

[12] Alimentación enteral del recién nacido prematuro menor o igual a 32 semanas de edad gestacional. México: Secretaría de Salud; 2010.

[13] Gallegos-Martínez J, Reyes-Hernández J. Representations of mothers/fathers about health and breastfeeding of the premature child in hospitals with and without certification Baby-Friendly Hospital Initiative. Acta Pediátrica de México. 2018; 39(2): 99-108. https ://doi.org/10.18233/APM39No2pp99-1081571

[14] Sassá AH, Schmidt KT, Rodrigues BC, et al. Preterm infants: Breastfeeding and weight gain. Rev Bras Enf (REBEn). 2014; 67(4): 594-600. PMid:25271585 https://doi.org/10.1590/0034-7 167.2014670415

[15] Velázquez-Barahoa G. Comparing the weight of premature babies fed exclusively on breast milk (emphasising hindmilk) to that of 
those receining mixed breastfeeding and those on human breast milk substitutes.Rev Fac Med. 2014; 62 Supl(1): 29-34.

[16] Giannì ML, Bezze E, Sannino P, et al. Facilitators and barriers of breastfeeding late preterm infants according to mothers' experiences. BMC Pediatrics. 2016; 16: 179. PMid:27821185 https: //doi.org/10.1186/s12887-016-0722-7

[17] Kair LR, Colaizy TT. Breastfeeding continuation among late preterm infants: barriers, facilitators, and any association with NICU admission? Hospital Pediatrics. May 2016; 6(5): 261-268. PMid:27048247 https://doi.org/10.1542/hpeds.2015-0172

[18] Alzaheb RA. Factors associated with the initiation of breastfeeding within the first 48 hours of life in Tabuk, Saudi Arabia. International Breastfeeding Journal, 2016; 11: 21. PMid:27446231 https://doi.org/10.1186/s13006-016-0079-4

[19] Maastrup R, Hansen BM, Kronborg H, et al. Factors Associated with Exclusive Breastfeeding of Preterm Infants. Results from a Prospective National Cohort Study. PLoS ONE. 2014; 9(2): e89077. PMid:24586513 https://doi.org/10.1371/journal.pone.0 089077

[20] Tan KL. Factors associated with exclusive breastfeeding among infants under six months of age in peninsular Malaysia. International Breastfeeding Journal. 2011; 6(2). PMid:21284889 https: //doi.org/10.1186/1746-4358-6-2

[21] Attanasio L, Kozhimannil KB, McGovern P, et al. The impact of prenatal employment on breastfeeding intentions and breastfeeding status at one week postpartum. J Hum Lact. 2013 November; 29(4). PMid:24047641 https ://doi.org/10.1177/08903344135041 49

[22] Hallowell SG, Spatz DL, Hanlon AL, et al. Characteristics of the NICU Work Environment Associated With Breastfeeding Support. Adv Neonatal Care. 2014 August; 14(4): 290-300. PMid:25075926 https://doi.org/10.1097/ANC.0000000000000102
[23] Hendaus M, Alhammadi AH, Khan S, et al. Breastfeeding rates and barriers: a report from the state of Qatar. International Journal of Women's Health. 2018; 10: 467-475. PMid:30174463 https : //doi.org/10.2147/IJWH.S161003

[24] Freitas BACh, Lima LM, Carlos Carla FLV, et al. Duration of breastfeeding in preterm infants followed at a secondary referral service. Rev Paul Pediatr. 2016; 34(2): 189-196. https ://doi.org/10.1 016/j.rppede.2016.02.010

[25] Warkentin S, Taddei JAAC, Viana KJ, et al. Exclusive breastfeeding duration and determinants among Brazilian children under two years of age. Rev. Nutr., Campinas. 2013; 26(3): 259-269. https://doi.org/10.1590/S1415-52732013000300001

[26] Kasahun AW, Wako WG, Gebere MW, et al. Predictors of exclusive breastfeeding duration among 6-12 month aged children in gurage zone, South Ethiopia: a survival analysis. International Breastfeeding Journal. 2017; 12: 20. PMid:28439290 https://doi.org/10.1 186/s13006-017-0107-z

[27] Dozier AM, Brownell EA, Thevenet-Morrison K, et al. Predicting Maintenance of Any Breastfeeding from Exclusive Breastfeeding Duration: A Replication Study. Jpediatr, 2018.

[28] Flacking R, Nyqvist KH, Ewald U. Effects of socioeconomic status on breastfeeding duration in mothers of preterm and term infants. European Journal of Public Health, 2007; 17(6): 579-584. PMid:17392294 https ://doi.org/10.1093/eurpub/ckm019

[29] Secretaría de Salud de México. Estrategia Nacional de Lactancia Materna 2014-2018.

[30] Jung Sh, Nobari TZ, Whaley ShE. Breastfeeding Outcomes Among WIC-Participating Infants and Their Relationships to Baby-Friendly Hospital Practices. Breastfeeding Medicine, 2019 In Press, a Mary Ann Liebert, Inc.

[31] Secretaría de Salud (SSA). Iniciativa Hospital Amigo del Niño y la Niña. 2015. 